\title{
Non-invasive assessment of oestrous cycles and evaluation of reproductive seasonality in the female wild black rhinoceros (Diceros bicornis minor)
}

\author{
J. N. Garnier ${ }^{1}$, W. V. Holt ${ }^{1}$ and P. F. Watson ${ }^{2}$ \\ ${ }^{1}$ The Zoological Society of London, Regent's Park, London NW1 4RY, UK; and 'Department \\ of Veterinary Basic Sciences, Royal Veterinary College, London NW1 OUT, UK
}

Female wild black rhinoceroses in Zimbabwe were monitored non-invasively using faecal progesterone metabolite analysis and observation of reproductive behaviour. A postpartum period of reproductive inactivity of at least 4 months, followed by a period of 4-7 months of oestrous cyclicity, was detected in six multiparous females. Threequarters of the oestrous cycles $(n=21)$ had a total duration (mean \pm SEM) of $26.8 \pm 1$ days. Other types of cycle were characterized either by an extended luteal phase, lasting on average twice as long as the normal cycle, or by an extended follicular phase. These extended cycles may have resulted from early embryo loss and heat stress. Female rhinoceroses did not conceive before 8 months after giving birth and some females $(n=2)$ most likely aborted after 3.0-3.5 months of gestation. The detected period of cyclic oestrus occurred between May and March in females $(n=9)$, and there was a 3 month extended interoestrous interval in nulliparous females during the period of decreasing daylengths that can be presumed to be the period of poorest fertility for the black rhinoceros under tropical latitudes. In contrast, the period of optimum fertility in the Southern hemisphere coincided with the late spring and early summer, and corresponded to the early rainy season. As a result, a higher incidence of births was detected in the late rainy season, providing the lactating female with the most suitable environment in terms of nutritional requirements.

\section{Introduction}

The Rhinocerotidae appeared during the early Eocene, some 50 million years ago, and represent one of the most ecologically diverse and widespread families of megaherbivores (Owen-Smith, 1988). Five rhinoceros species survive today, all of which are endangered, and comprise a total of < 15000 animals (Foose and Van Strien, 1997; Emslie and Brooks, 1999). The population of black rhinoceroses was estimated to be only 2600 in 1997 (Emslie and Brooks, 1999).

As a result of the demand for rhinoceros horn, the remaining rhinoceros populations are exposed to a permanent threat of poaching. These populations are small and isolated, making them also vulnerable to stochastic environmental, demographic or genetic factors (Bride et al., 1996). Remaining populations must present optimum breeding output, both in the wild and in captivity, which is far from being achieved (Lindemann, 1982; Kock and Garnier, 1993; Brett, 1998; Göltenboth, 1999; Garnier, 2001).

The first obstacle in attaining optimum reproductive performances in black rhinoceroses is the difficulty of assessing reproductive success in an animal with such a long generation period, solitary habits and which lives in dense habitats at low densities (Ritchie, 1963; Goddard,

Email: juliegarnier@hotmail.com
1967; Shenkel and Shenkel-Hulliger, 1969; Joubert and Eloff, 1971; Adcock, 1994). As a result of this difficulty, simple reproductive parameters are generally based on a limited number of observations and can give information only retrospectively. Measurements neither reflect individual variations nor indicate a potential decline in fertility. Such information is also difficult to interpret because so little is known of reproductive features of the rhinoceros.

The information available on oestrous cycles and seasonality in free-ranging black rhinoceroses is rare and anecdotal. One study established that interoestrous intervals ranged from 26 to 46 days (Hitchins and Anderson, 1983). Oestrous behaviour in the wild has been described by Brett et al. (1989), Goddard (1966), Hitchins and Anderson (1983) and Shenkel and Shenkel-Hulliger (1969) and the period from the first day of attendance by the bull to the time of copulation is reported to be 6-7 days and the duration of receptivity only 1-3 days. Some peaks in parturition have been identified in southern Africa at different times of the year (Joubert and Eloff, 1971; HallMartin and Penzhorn, 1977; Hitchins and Anderson, 1983). In east Africa, little or no evidence of reproductive seasonality has been found (Ritchie, 1963; Goddard, 1967; Shenkel and Shenkel-Hulliger, 1969).

In captivity, individual interoestrous intervals of rhinoceroses ranged from 17 to 83 days (Lindemann, 1982). Hindle et al. (1992) used an enzymeimmunoassay for 
Table 1. Types and periods of data collection in each study area in the present study of female black rhinoceroses

\begin{tabular}{|c|c|c|c|c|c|}
\hline \multirow[b]{2}{*}{ Location } & \multicolumn{2}{|c|}{ Study animals } & \multicolumn{3}{|c|}{ Type of data collected and date collected } \\
\hline & Animals & Year of birth* & Hormonal $^{+}$ & Behavioural $^{\ddagger}$ & Demographic $\$$ \\
\hline \multirow[t]{7}{*}{ Save Valley } & Bulawayo & 1962 & $5 / 96-4 / 98$ & $5 / 96-4 / 99$ & 3/94-3/99 \\
\hline & Pukwani & 1960 & $5 / 96-2 / 98$ & $5 / 96-4 / 99$ & 3/94-3/99 \\
\hline & Netsai & 1967-1972 & $5 / 96-3 / 98$ & $5 / 96-4 / 99$ & 3/94-3/99 \\
\hline & Sirica & 1962 & $5 / 96-7 / 98$ & $5 / 96-4 / 99$ & $3 / 94-3 / 99$ \\
\hline & Jete & 1990 & $5 / 96-4 / 98$ & $5 / 96-4 / 99$ & $3 / 94-3 / 99$ \\
\hline & Sara & 1989 & $1 / 97-11 / 98$ & $5 / 96-4 / 99$ & 3/94-3/99 \\
\hline & Other females $(n=8)$ & & None & None & 3/94-3/99 \\
\hline Imire & Amber, Mvu, DJ & 1987 & None & 9/94-3/98 & 9/94-3/98 \\
\hline London & Rosie & 1988 & 5/96-2/97 & $5 / 96-2 / 97$ & None \\
\hline
\end{tabular}

Dates indicate periods during which each type of data was collected.

*The age of the first four animals from the Save Valley Conservancy had been determined during previous immobilization procedures by evaluating the toothwear pattern, whereas the dates of birth of the other study animals were recorded.

†Faecal samples were collected every 2-3 days during the dry season and every 4-5 days during the rainy season.

${ }^{\ddagger}$ Reproductive behaviour was recorded at the same frequency as for the collection of faecal samples.

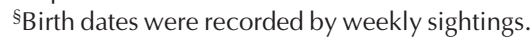

measuring urinary $20 \alpha$-dihydroprogesterone to establish that an average cycle duration of 21 days was represented by a $16-17$ day luteal phase with a 3-4 day follicular phase in two captive females. Radcliffe et al. (2001) observed an interovulatory period of 26 days during two cycles by combining ultrasound examination and faecal progesterone metabolite analysis.

The collection of faecal samples represents a practical approach for monitoring reproduction under free-ranging conditions, and the analysis of faecal steroid metabolites has been used to assess breeding activity in an increasing number of species, especially in captivity (for a review, see Schwarzenberger et al., 1996a). In the wild, the use of faecal steroid analysis has been limited to populations or social groups in a very limited number of species (see Monfort, in press).

In rhinoceros species, faecal progestagen analysis has permitted the monitoring of gestation and diagnosis of pregnancy in both wild and captive black and white rhinoceroses (Schwarzenberger et al., 1993, in press; Berkeley et al., 1997; Radcliffe et al., 1997; Garnier et al., 1998a; Patton et al., 1999), and in captive Indian rhinoceroses (Schwarzenberger et al., 2000). The analysis of faecal progestagen has also allowed the assessment of luteal activity in captivity in white (Patton et al., 1999), Indian (Schwarzenberger et al., 2000) and Sumatran rhinoceroses (Heistermann et al., 1998).

The main objective of the present study was to characterize the reproductive cycles and patterns of seasonality in black rhinoceroses in their natural environment. In particular, the study aimed to: (i) monitor oestrous cycles during the intergestation period in wild females using faecal progestagen analysis; and (ii) assess the influence of seasonality on reproductive activity.

\section{Materials and Methods}

Study site

The study was conducted in Zimbabwe in two different sites: the Save Valley Conservancy (SVC; 20E, 31S), which covers $3387 \mathrm{~km}^{2}$ in the south-east of the country, and the smaller Imire game ranch $(18 \mathrm{E}, 31 \mathrm{~S})$, which covers $300 \mathrm{~km}^{2}$ in the Midlands area. The climate in Zimbabwe consists essentially of a rainy season lasting 5 months (November until April), and the average rainfall is lower in the south $(300-500 \mathrm{~mm})$ than in the Midlands $(600-800 \mathrm{~mm})$. The dry season can be divided into a cold period (May to mid-August) and a hot period (mid-August to October). Temperatures reach peak values in October.

\section{Animals and data collection}

The study animals in the SVC were located in the southern section of the area, where a resident sub-population originated from 20 black rhinoceros translocated there in 1986-1988. This sub-population consisted of 43 animals in March 1999; it had a mean adult sex ratio of 1.2 males: 1 female and a mean proportion of adults of $56 \%$ between 1994 and 1999, during which time there was a recruitment rate of $7.2 \%$ (Garnier, 2001).

Individual reproductive monitoring was undertaken in six wild females, including four founder animals (Pukwani, Bulawayo, Netsai and Sirica) and two first generation animals (Jete and Sara) after they gave birth. The two first generation animals were 6 and 10 years old, respectively, when parturition was recorded during the study, and the founder animals were estimated to be between 25 and 37 years old at that time. The female Pukwani belonged to a different community of black rhinoceroses compared with 
the other females studied and interacted with different males. Reproductive monitoring in the animals included the collection of both hormonal and behavioural data for the six females mentioned above during 2 and 3 years, respectively, as well as the recording of birth dates for all females in the southern section of SVC during a 5 year period (Table $1)$. The duration of gestation for these females was described by Garnier et al. (1998a).

Reproductive monitoring followed the method of Garnier et al. (1998a). Briefly, animals were identified and located regularly using either tracking with local game scouts or radio-telemetry (only one female had a radiocollar during the study). A fresh faecal sample was collected (Garnier et al., 1998b) and the animal was sighted (located and observed), unless conditions for its close approach were not favourable. Most sightings were of short duration (5-10 $\mathrm{min})$ to avoid the detection of our presence by the animals. During each sighting, reproductive behaviour was recorded, including flehmen, mounting, mating, the frequent squirting of small amounts of urine (urine-marking), fighting between males, as well as male-female consortship, as previous studies indicated that a male starts to consort with a female after he has detected that she is approaching oestrus (Goddard, 1966; Shenkel and Shenkel-Hulliger, 1969; Brett et al., 1989).

Consortship with males was assessed by recording direct observations of male-female interactions. Both adult and sub-adult males were considered, as records from captive animals indicate that males can sire from as early as 4.5 years of age (Rookmaker, 1998), although males are only usually considered to be adults in the wild when $>8$ years of age (Hitchins and Anderson, 1983; Owen-Smith, 1988).

Hormonal and behavioural data collection was conducted every 2-3 days for two females (Sara and Bulawayo) that gave birth after the rainy season and could be located easily after parturition. In the other four females (Jete, Sirica, Pukwani and Netsai), which gave birth during the rainy season when locating the animals is more difficult (Garnier et al., 1998a), hormonal and behavioural data were collected at an average of once every 4-5 days until July and thereafter every 2-3 days. This monitoring frequency lasted until the females became pregnant again, as detected by faecal progestagen analysis (Garnier et al., 1998a). The detection of births outside the above period was undertaken through weekly sightings of the females.

In the Imire game ranch, three adult females (Mvu, DJ and Amber) were studied in a semi-wild population of seven adult black rhinoceros (three males and four females). All animals had been hand-raised and were estimated to have been born in 1987. Animals were kept in a common enclosure at night and let out to feed on natural vegetation during the day, under constant surveillance. Reproductive behaviour was recorded each day for 4 years, and birth dates were recorded (Table 1). Calves at Imire were separated from their mother at approximately 6-7 months of age, after which time they were hand-reared. Females returned into oestrus within 1 week of removal of the calf
(Garnier, 2001); therefore, only the first parturition was recorded in each female, as artificial weaning of the calf might have interfered with naturally occurring periods of reproductive inactivity.

Both wild and semi-wild situations are characterized by a natural breeding system (Bride et al., 1996) and both wild and semi-wild females are hereafter referred to as 'wild'.

One captive black rhinoceros female (Rosie) kept at London Zoo was also studied. She had been hand-reared and was estimated to be 8 years old during the study. She was paired with a male in an outdoor paddock during periods of sexual receptivity, when the male showed increased interest towards her, and when climatic conditions (temperature and humidity) were favourable. Both hormonal and behavioural data were collected every day for 9 months (Table 1). This female did not produce a calf and was subsequently transferred to another institution.

\section{Hormonal analysis}

Faecal samples were collected by breaking apart a fresh faecal pellet and placing an amount equivalent to a handful into polythene bags using a wooden stick. A sample was considered to be fresh when the superficial layer of faecal pellets was still wet and no insect contamination had occurred (Garnier et al., 1998b). Samples were placed in a thermos flask that had been stored at $4^{\circ} \mathrm{C}$ until they could be stored in an electrical cool box in the car, which occurred between $30 \mathrm{~min}$ and $4 \mathrm{~h}$ after the sample collection. Faecal samples were transferred to permanent freezing facilities and stored at $-18^{\circ} \mathrm{C}$ after returning to the research base. Samples were thawed and dried at $65^{\circ} \mathrm{C}$ for $18 \mathrm{~h}$ in an oven (Labotec, Johannesburg). Eighteen hours was initially estimated to be sufficient to remove the moisture content from faecal samples, on the basis of visual and tactile examination of samples. A subsequent trial involving the regular weighing of samples throughout the drying process showed that the weight of samples became stable after $12 \mathrm{~h}$ of drying. Samples were brought back to London every year to be analysed in batches.

Faecal progestagen analysis followed a method described and validated in wild black rhinoceros (Garnier et al., 1998a). Briefly, steroids were extracted by combining $0.1 \mathrm{~g}$ dry faeces with $0.2 \mathrm{~g}$ aluminium oxide, $0.6 \mathrm{ml}$ methanol and $0.5 \mathrm{ml}$ distilled water. Faecal progestagens were then measured with an enzymeimmunoassay that used an anti-20 $\alpha$-dihydroprogesterone (20 $\alpha$-OHP) antibody which had been validated for urinary steroid analysis during oestrous cycles in African rhinoceroses (Hindle et al., 1992) and for faecal steroid analysis during pregnancy in wild black rhinoceroses (Garnier et al., 1998a). The enzymeimmunoassays were performed in microtitre plates coated with an anti-lgG antibody, using a double antibody technique. The antibody was raised in rabbits immunized against $20 \alpha-\mathrm{OHP}$ conjugated to BSA through carboxymethyloxime (donated by M. J. Peddie, Department of Physics and Pharmacy, University of Southampton). The 


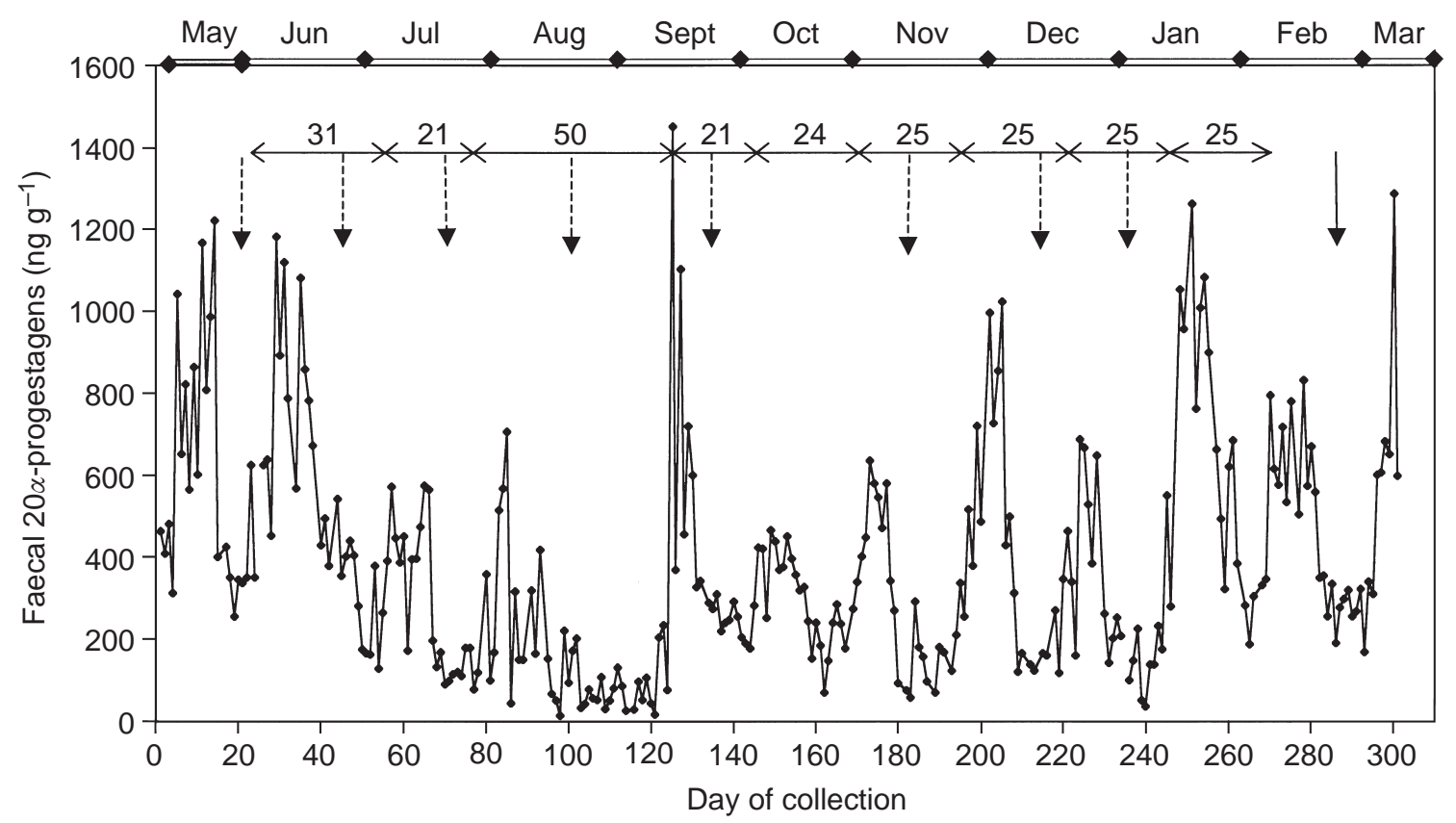

Fig. 1. Concentrations of faecal $20 \alpha$-progestagens in a captive female (Rosie) nulliparous black rhinoceros (Diceros bicornis minor) from May 1996 to February 1997. The female was isolated from the male between day 236 and day 271 of the profile. Vertical arrows indicate reproductive activity (a complete line indicates mating and broken lines indicate chasing by a male with an erection, fighting and mounting). Horizontal arrows indicate the duration (days) of the oestrous cycle, defined as the interval between successive periods of sustained increased faecal progestagen concentrations.

enzyme label was biotin conjugated to $20 \alpha-\mathrm{OHP}$ (donated by E. Möstl, Institut für Biochemie, Veterinärmedizinische Universität, Vienna).

\section{Data manipulation and statistical analysis}

Oestrous cycles. The initial observation of intergestation profiles showed differences in background concentrations of progestagen in each profile. For this reason, each intergestation period was divided into distinct periods, 11-I4. The definition of each period corresponded to the part of the profile that presented similar background concentrations, although the distinction between one period and the next was determined subjectively. Mean background concentrations for each period were calculated subsequently by removing progressively higher and lower values from the original data set until the coefficient of skewness was no longer significant and then by calculating the mean of the remaining concentrations (Brinkley, 1991). Differences between mean background concentrations were tested by one-way ANOVA.

A cyclic pattern was identified on the basis of endocrine criteria, when two consecutive values below mean background concentrations were followed by a sustained increase in faecal progestagen concentrations above mean background concentrations, before decreasing again to a nadir of at least two consecutive values below mean background concentrations. An increase of concentrations above mean background concentration was considered to be sustained if two of three consecutive values were above mean background concentration.

The duration of the cycle was defined as the time interval between the first day of successive periods of sustained increase in faecal progestagen concentrations as defined above. Cycle analysis applied only to parts of the hormonal profile that had no sampling interval $>6$ days, as a longer sampling interval could result in the lack of identification of the period of low progestagen concentrations. This restriction is based on the results obtained (see below) and on previous reports that periods of reproductive activity in wild black rhinoceros females lasted 6-7 days (Hitchins and Anderson, 1983). As samples were not collected every day, the number of days between the end of the period of high concentrations and the subsequent period of low concentrations was divided equally between the two periods. The same principle applied between the end of a period of low concentrations and a subsequent period of high concentrations.

Subsequently, cycles were categorized into different types. Cycles that were the most represented and the total durations of which best fitted a normal distribution were found to have a total duration $\leqslant 40$ days and were categorized as type I cycles. Type II cycles had a total duration of $>40$ days and were further classified into type lla cycles, with a period of low concentrations $\leqslant 15$ days, and type Ilb cycles, with a period of low concentrations $>15$ days. 

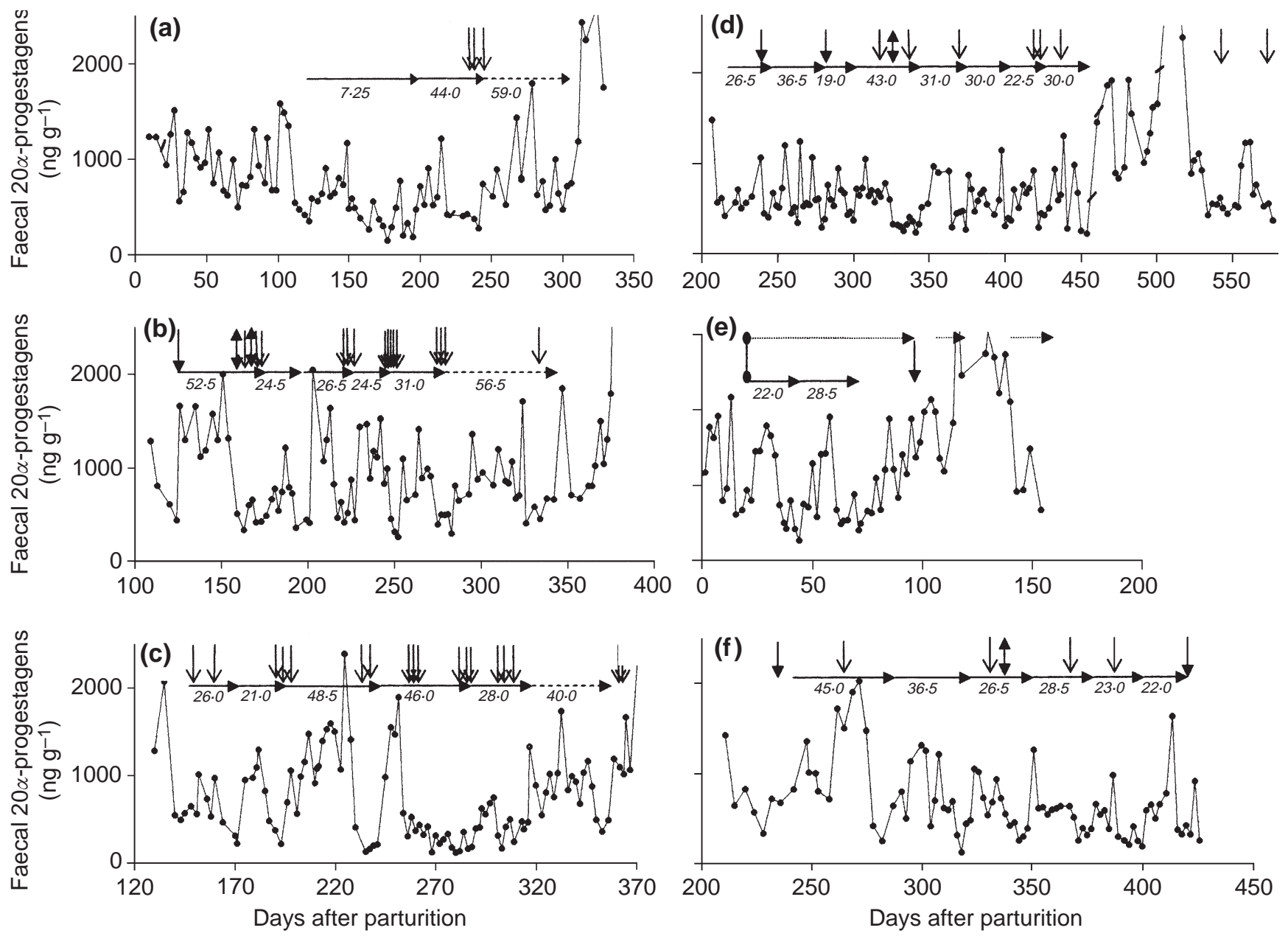

Fig. 2. Concentrations of faecal $20 \alpha$-progestagen in six female wild black rhinoceroses (Diceros bicornis minor) after parturition, and during reproductive cycles and early pregnancy. Vertical arrows indicate interactions with the dominant adult male, full arrowheads indicate mating and double headed arrows indicate fighting between males. Vertical lines with a double rounded end indicate calf death. Horizontal unbroken lines with arrows indicate the duration (days) of the cycle, dashed lines (---) the cyclic variations during the early pregnancy phase, and dotted lines $(\cdots)$ the continuous presence of an adult male. Short diagonal lines $(/)$ indicate a sampling interval $>6$ days. Female rhinoceroses are (a) Bulawayo, (b) Netsai, (c) Pukwani, (d) Sirica, (e) Sara and (f) Jete.

Comparisons between cycle durations were made using the Mann-Whitney U test.

Intervals between interactions with males were calculated by measuring the interval between the first days of periods of observed interactions, considering only intervals that were $>10$ days, as periods of interactions with the same male could last as long as 12 days.

Seasonality. Seasonality was assessed by: (i) aligning the periods of ovarian cyclic activity and gestation with the time of the year; (ii) assessing the relative proportion of reproductive cycles of types I and II for each month; and (iii) assessing the monthly distribution of births. The beginning of periods of cyclic activity was determined using the results of faecal steroid analysis and behavioural observations for the six females studied in the SVC, and through observations of behavioural oestrus in the three females studied in the Imire game ranch. On the basis of the findings of the present study, cycles determined through behavioural observations at Imire were also categorized into two types: duration of type I cycles was $\leqslant 40$ days and duration of type II cycles was $>40$ days. The monthly assessment of type of reproductive cycle used dates related to the onset of the luteal phase for cycles determined by faecal steroid analysis and dates related to the first signs of oestrous behaviour for cycles determined through behavioural observations.

The proportions of births in the dry and rainy seasons were compared using a chi-squared test with Yates' continuity correction.

\section{Results}

Validation of the enzymeimmunoassays for progestagen measurement during oestrous cycles

A cyclic pattern of variations of faecal $20 \alpha$-progestagens was obtained in the captive female monitored for 9 months 


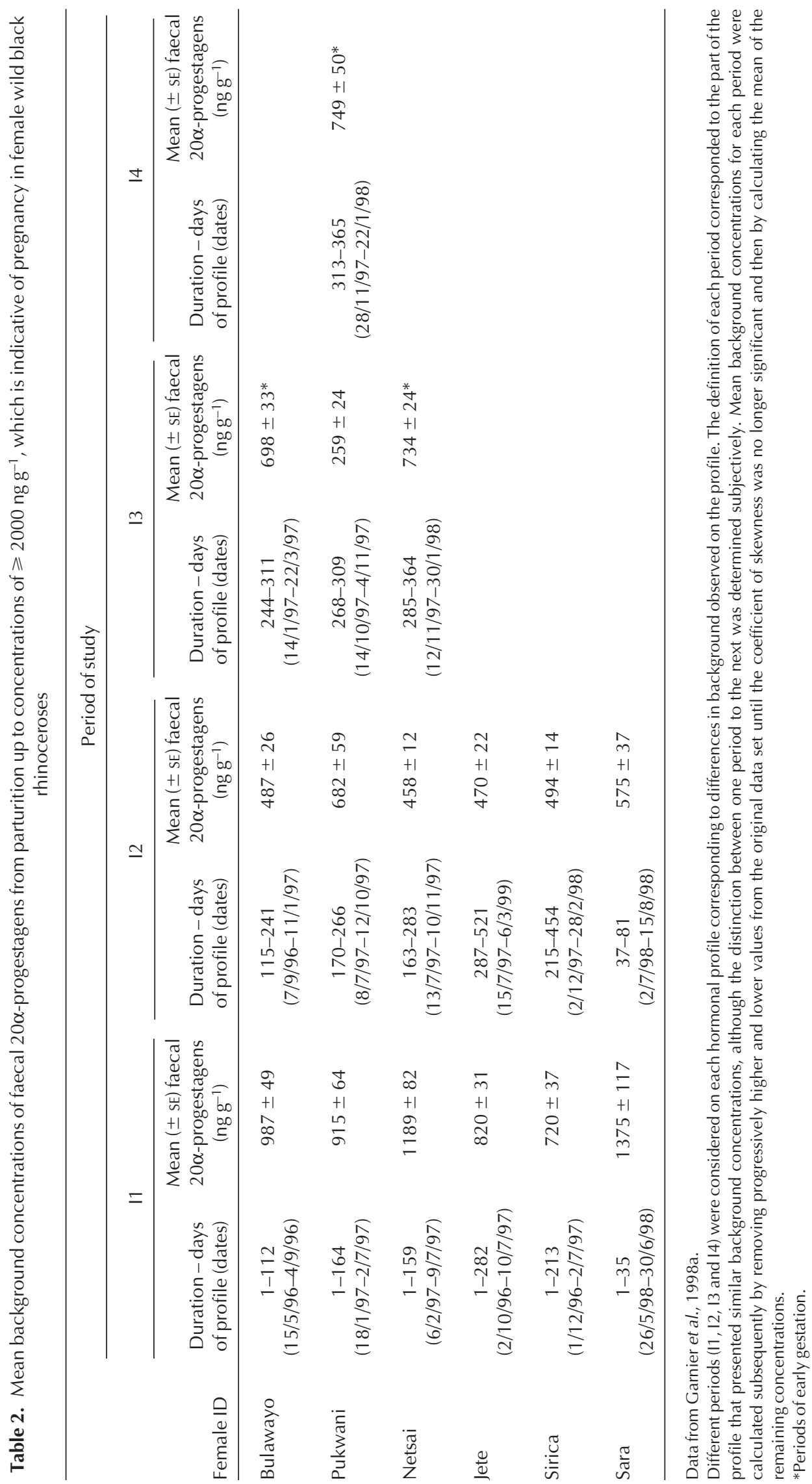


(Fig. 1). The hormone profile showed cyclic fluctuations of faecal progesterone metabolite concentrations. Periods of high concentrations of faecal 20 $\alpha$-progestagens, lasting an average of $15 \pm 1.5$ days (range $9-26$ days, $n=11$ ), were followed by periods of low concentrations, which lasted an average of $11.6 \pm 2.1$ days (range 5-29 days, $n=11$ ). Reproductive activity lasted up to 4 days in this female and occurred either just before or during periods of low concentrations of faecal $20 \alpha$-progestagens. Concentrations of

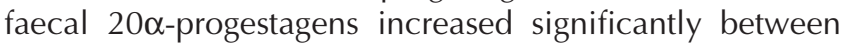
day 5 and day 12 after the first signs of reproductive activity were observed. The only time when behavioural observations of oestrus and hormonal variations were not related was represented by the absence of oestrous behaviour at about day 160, although a marked decline in faecal $20 \alpha$ progestagens occurred.

\section{Individual hormone profiles}

Three wild females showed no interaction with an adult male during the first 4.0-4.5 months after parturition (Fig. $2 \mathrm{a}-\mathrm{c})$, whereas two females only resumed regular interactions with males 7-8 months after parturition (Fig. $2 d, f$ ). In the female whose calf was killed by lions at 3 weeks of age (Fig. 2e), the resumption of interactions with males occurred within 2 days after the calf died. In all females, the postpartum period was characterized by a higher mean background concentration of faecal 20 $\alpha$-progestagens (700-1400 ng g-1) compared with subsequent intergestational periods during which it was about $500 \mathrm{ng} \mathrm{g}^{-1}$ (Table 2). During this postpartum period of behavioural reproductive inactivity, faecal progesterone metabolite concentrations were fluctuating (as shown in Fig. 2a), but statistical analysis did not reveal any clear cyclic pattern.

Individual hormonal profiles in six wild females showed between two and eight cyclic variations of faecal $20 \alpha$ progestagen concentrations in each female, occurring between 4 and 15 months after parturition (Fig. 2). The last cyclic variation detected on some profiles (Fig. 2a-c) occurred before the sustained increase in faecal $20 \alpha$ progestagens to concentrations $>2000 \mathrm{ng} \mathrm{g}^{-1}$ and simultaneously with a significant increase in mean background concentration $(P<0.01)$, indicating that these females were already in a phase of early pregnancy (Table 2). However, in two females, the sustained increase of faecal $20 \alpha$ progestagens to concentrations $>2000 \mathrm{ng} \mathrm{g}^{-1}$ was followed by an abrupt decline in concentrations between day 70 and day 100 after presumed conception (Fig. 2d,e). Such a marked and rapid decrease in concentrations, associated with the resumption of regular interactions with males and of cyclic variations in faecal $20 \alpha$-progestagen concentrations, indicates that there is a very strong probability that these two females aborted.

Each female interacted with between one and three adult males, and with up to two sub-adults. One male always dominated the consortship for a female and consequently will be called the dominant male for that female. Inter- actions with dominant males represented between 38 and $100 \%$ of interactions with both adult and sub-adult males. In all cases, it was the dominant male that was observed to mate the female and to fight with other males. Most observations of consortship with the dominant male were coincidental with periods of low concentrations of faecal 20 $\alpha$-progestagens, whereas periods of consortship with other males, including sub-adults, could occur during periods of high concentrations. Significant increases in faecal 20 $\alpha$-progestagens were detected within 6 days after the observation of mating, although in one instance it was detected 1 day before the observation of mating activity. One female mated after presumed conception (Fig. 2e).

There were great individual differences in the number of male interactions recorded for each female and some females continued interacting with their previous male calves. Such consortship represented up to $25 \%$ of all direct observations recorded. As a result, associations of up to five animals were seen, including the breeding male, the cowcalf unit and her two previous calves.

\section{Durations and types of cycle}

The different types of cycle established from individual cycles $(n=27)$ obtained in the six females studied are presented (Table 3). Type I cycles were most frequent and were characterized by a total duration of $26.8 \pm 1$ days (mean $\pm \mathrm{SE}$ ) and by periods of high and low concentrations of faecal $20 \alpha$-progestagens of $18 \pm 1.1$ days and $9 \pm 0.5$ days, respectively. Type lla cycles were detected during the first half of the hormonal profiles of two study animals and were preceded by the observation of mating activity (Fig. 2b,f). However, the fluctuations of $20 \alpha$-progestagen concentrations that were observed during early pregnancy in three animals (Fig. 2a-c) had the same characteristics as type Ila cycles (total duration of $\geqslant 40$ days and period of low $20 \alpha$-progestagen concentrations $\leqslant 15$ days) and all were associated with a significantly longer period of high $20 \alpha$-progestagen concentrations compared with type I cycles $(P<0.001)$.

Type Ilb cycles presented a significantly longer period of low 20 $\alpha$-progestagen concentrations compared with type I cycles $(P<0.001)$. Such cycles were identified once in four of the six females studied. Of these cycles, two cycles were associated with the observation of a fight between males

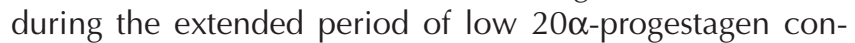

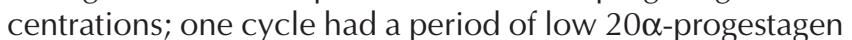
concentrations surrounded by two periods of consortship with males; and one cycle was not associated with any interactions with males.

Type I cycles represented $75 \%(n=21)$ of all cycles, whereas type Ila cycles represented at least $7 \%(n=2)$ and type IIb at least $13 \%(n=4)$ of all cycles (one type II cycle could not been classified definitively as type Ila or IIb).

\section{Periods of reproductive activity}

The periods of post partum, oestrous cyclicity and gestation recorded in the six multiparous females studied 
Table 3. Characteristics of the different types of oestrous cycle in six female wild black rhinoceros (Diceros bicornis minor)

\begin{tabular}{lccc}
\hline & \multicolumn{3}{c}{ Type of cycle } \\
\cline { 2 - 4 } & $\begin{array}{c}\text { Type } \mathrm{I}^{\mathrm{a}} \\
(n=21)\end{array}$ & $\begin{array}{c}\text { Type Ila } \\
(n=2)\end{array}$ & $\begin{array}{c}\text { Type Ilb }^{\mathrm{c}} \\
(n=4)\end{array}$ \\
\hline Total duration of oestrous cycle (days) & $26.8 \pm 1.0$ & 46.7 & $53.0 \pm 6.6$ \\
& $(19-36)$ & $(45-48)$ & $(43-72.5)$ \\
Duration of maintenance of high concentrations & $18.0 \pm 1.1$ & 35.7 & $23.1 \pm 4.6$ \\
of faecal progestagen (days) & $(10-30)$ & $(34-37)$ & $(10-31)$ \\
Duration of maintenance of low concentrations & $9.0 \pm 0.5$ & 11 & $30.3 \pm 6.3$ \\
of faecal progestagen (days) & $(6-13)$ & $(8-14)$ & $(19-45)$ \\
\hline
\end{tabular}

Values are mean \pm SEM. Values in parentheses indicate range.

aTotal duration of the cycle $<40$ days.

bTotal duration of the cycle $\geqslant 40$ days and period of low faecal progestagen concentrations $\leqslant 15$ days.

'Total duration of the cycle $\geqslant 40$ days and period of low faecal progestagen concentrations $>15$ days.

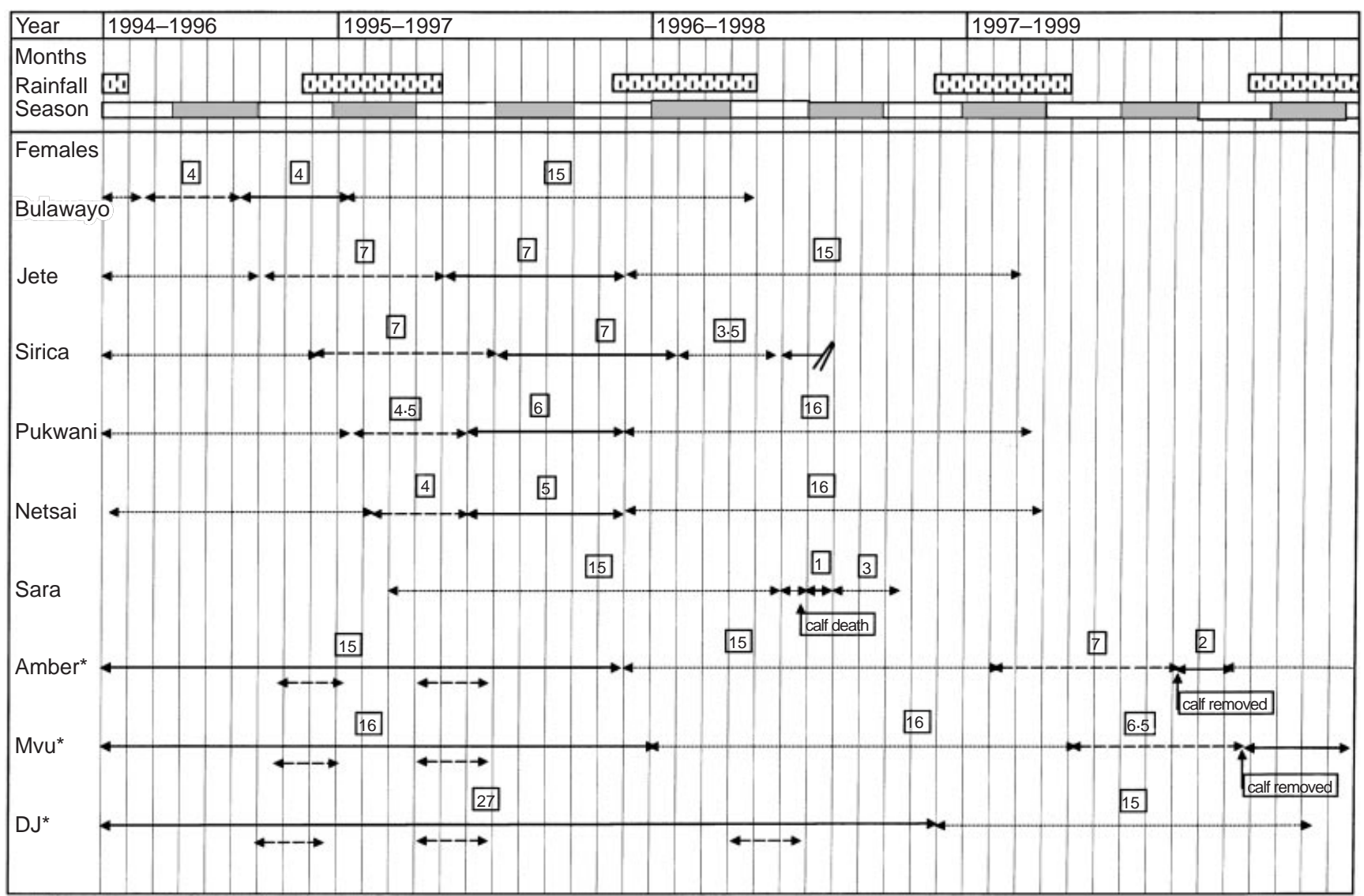

Fig. 3. Annual reproductive cycles in female wild black rhinoceroses (Diceros bicornis minor), including multiparous and nulliparous females. Asterisks indicate nulliparous females. The first six females in the list were studied in 1996-1999, whereas the last three females were studied in 1994-1997. Dotted lines (...) indicate periods of gestation or periods during which faecal 20 $\alpha$-progestagen concentrations increased to $>2000 \mathrm{ng} \mathrm{g}^{-1}$. Dashed lines (---) indicate a postpartum period without detected oestrous behaviour in multiparous females or an inter-oestrous interval of $>60$ days in nulliparous females. Complete lines indicate periods of oestrous cyclicity. Values in boxes indicate the duration (months) of each period. 

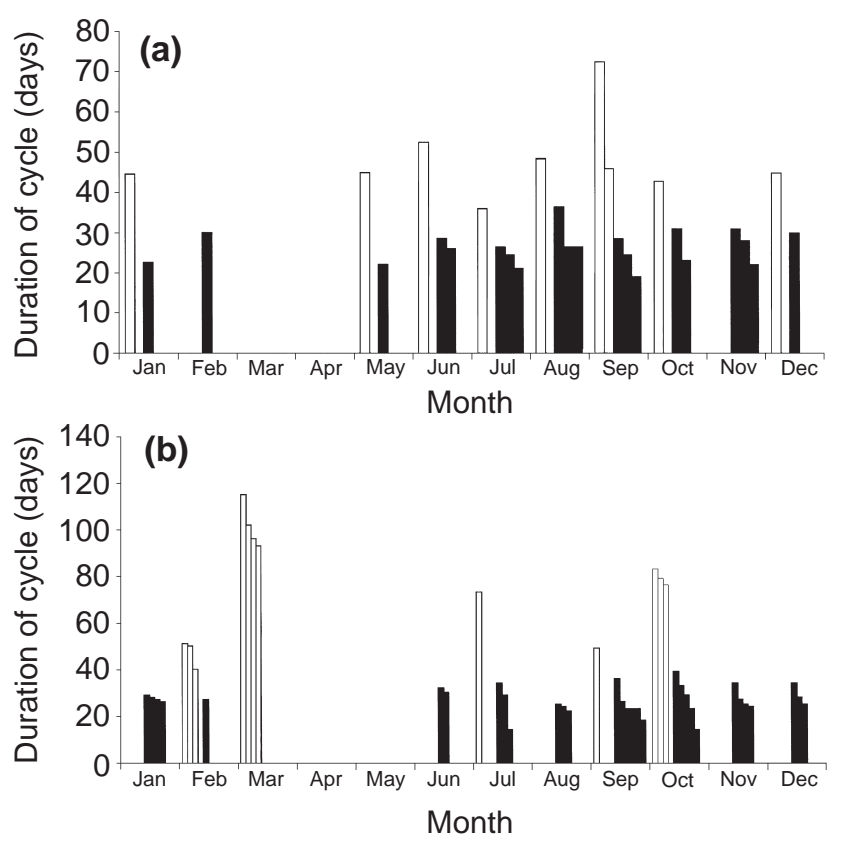

Fig. 4. Monthly distribution of type I ( $\mathbf{\square}$; duration $<40$ days) and type II ( $\square$; duration $\geqslant 40$ days) reproductive cycles in individual (a) multiparous and (b) nulliparous female wild black rhinoceroses (Diceros bicornis minor).

above were aligned by months (Fig. 3). Periods of oestrous cyclicity started in May-June in four females and lasted between 4 and 7 months, except for the female whose calf died, for whom oestrous cyclicity lasted 1 month. In females whose calves stayed alive, all conceptions $(n=6)$ determined through faecal steroid analysis occurred in NovemberFebruary, corresponding to the early rainy season and late spring-early summer, and half of these were detected in November. As a result, all females (except the two females that presumably aborted) gave birth in March-May, that is, during the late and after the rainy season.

In nulliparous females, periods of reproductive cyclicity lasted more than 1 year in two females (Amber, Mvu) and more than 2 years in one female (DJ) (Fig. 3). An extended interoestrous interval of about 2.5 months was observed in all females in October-December 1994. Other extended interoestrous intervals of 3.0-3.5 months were detected every year in April-June and were extremely synchronized among females (Amber, Mvu, DJ), beginning between 19 and 24 March and ending between 25 June and 12 July. These females conceived between the end of November and January. Two of these females did not interact with any male until about 7 months after parturition, after which time their calves were removed to be hand-reared. These females conceived 9 days and 2 months, respectively, after removal of their calves.

\section{Distribution of cycle durations}

The monthly distribution of cycle durations in multi-

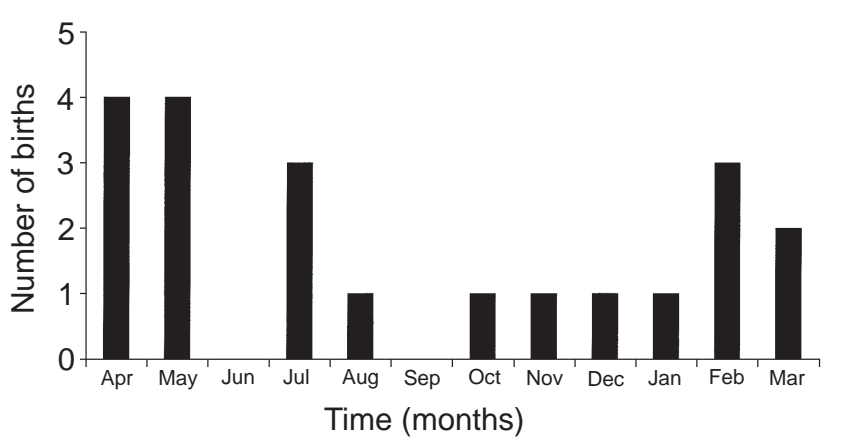

Fig. 5. Number of births $(n=21)$ each month in female wild black rhinoceroses (Diceros bicornis minor) in Zimbabwe.

parous females (Fig. 4a) shows that type I and type II cycles were recorded between May and February.

In nulliparous females (Fig. 4b), type I cycles occurred every month from June to February, but predominated between November and January. Type II cycles prevailed in February-March and in October.

\section{Distribution of births}

The monthly distribution of births $(n=21)$ recorded during the study (Fig. 5) shows that the proportion of births recorded in December-May (71\%) was significantly higher than in June-November (chi-squared $=3.85, P=0.05$ ). In fact, more births (62\%) occurred between February and May, coinciding with the late rainy season, reflecting peak conception between November and February, that is, during the early rainy season. However, four births were also recorded in mid-winter in July and August, two of which were observed in nulliparous females.

\section{Discussion}

The individual monitoring of six wild females in Zimbabwe showed that they did not conceive before 8 months after parturition when their calves survived and that they had very limited or no contact with males for 4-7 months after parturition. This is the first report of a postpartum period of reproductive inactivity in black rhinoceroses, although postpartum anoestrus has been reported in captive white and Indian rhinoceroses (of 3-4 months duration for Indian rhinoceroses; Schwarzenberger et al., 1999; Rietschel, 2000).

The hormone profiles obtained in females that could be monitored frequently during this period of reproductive inactivity showed fluctuating faecal progesterone metabolite concentrations and a high background concentration. Although there is no evidence that these progesterone metabolites were of ovarian origin, this finding may indicate that ovaries start to develop follicles shortly after parturition, as results from previous studies showed that follicular maturation resumed within 2-4 weeks after birth in some captive 
black rhinoceros females (Hindle, 1991; Berkeley et al., 1997). However, the death or removal of a black rhinoceros calf shortened the period of reduced reproductive activity, indicating that expression of reproductive behaviour is inhibited by the suckling stimulus. Therefore, the postpartum period in the black rhinoceros is similar to that of many mammals, in which ovulation and oestrus are delayed by the suckling stimulus (Cupps, 1991; Youngquist, 1997). The mechanisms by which the suckling stimulus inhibits oestrous behaviour could not be determined during the present study. However, the higher mean background of faecal progestagen concentrations may reflect the luteinization of follicles that develop during this phase, as high background concentrations of faecal progestagens have been reported to be indicative of persistent luteal activity in captive white rhinoceroses (Schwarzenberger et al., 1998).

Periods of oestrous cyclicity lasted between 4 and 7 months and were characterized by a great variability in cycle duration. Three-quarters of all cycles were classified as type I and presented a mean total duration of $26.8 \pm 1$ days, which is in agreement with other reports of cycle durations in this species (Lindemann, 1982; Hitchins and Anderson, 1983; Godfrey et al., 1991; Hindle et al., 1992; Schwarzenberger et al., 1993; Berkeley et al., 1997; Radcliffe et al., 2001). Most observations of reproductive activity (for example, a fight between males, periods of prolonged interactions with the dominant male and mating) occurred during periods of low faecal progesterone metabolite concentration and were followed by a significant increase in faecal progesterone metabolite concentration. Therefore, in type I cycles, periods of low faecal progesterone metabolite concentration are associated with the follicular phase of an ovarian cycle, whereas periods of high concentrations are associated with the luteal phase.

A lag of variable duration (5-12 days) was observed between the observation of reproductive activity and a significant increase in concentrations of faecal progesterone metabolites. Part of this lag may be attributable to the delay coinciding with the entero-hepatic circulation and faecal excretion of steroids, estimated to be 2-3 days in rhinocerotids (Hindle and Hodges, 1990; Heistermann et al., 1998), as well as to the delay of 2-3 days observed between onset of oestrus and ovulation in black rhinoceroses (Radcliffe et al., 2001). In addition, another interval probably occurs between ovulation and the subsequent increase in faecal progestagens, as has been described in white rhinoceroses (Radcliffe et al., 1997; Schwarzenberger et al., 1999).

One of the unexpected findings of the present study was the natural occurrence of extended cycles classified as type II, which were approximately twice as long as type I cycles. The observation of these cycles was unlikely to have been caused by a failure to detect a change in concentrations as the sampling frequency was very high during the period involved (every 2-3 days). Type II cycles were charac- terized by either a prolonged luteal phase or by an extended follicular phase.

A plausible explanation for these prolonged luteal phases is embryo loss. This pathology has been identified in three captive white rhinoceros females, and the corresponding luteal phases, identified by faecal pregnane analysis, lasted about twice the average cycle duration (Radcliffe et al., 1997; Patton et al., 1999). These reports, combined with the fact that a history of mating followed by anoestrus without pregnancy in mares is indicative of early embryo loss (Youngquist, 1997), indicate that such pathology may be associated with type Ila cycles. The fact that extended luteal phases were detected during the early gestation period in the present study reinforces this hypothesis. In contrast, type Ila cycles are unlikely to be associated with persistent luteal activity, a condition that occurs frequently in captive white rhinoceroses but which results in different hormone patterns (Schwarzenberger et al., 1998).

Type IIb cycles were characterized by an extended follicular phase and were anovulatory. The fact that most of these cycles occurred in October, which is the hottest time of the year in Zimbabwe and the time during which nulliparous females exhibit an extended interoestrous interval, indicates that these cycles may be caused by heat stress. This hypothesis is corroborated by the observation that freeranging white rhinoceroses did not exhibit oestrous behaviour when dry conditions prevailed (Owen-Smith, 1988). Heat stress is known to affect follicular growth, to decrease the duration of oestrous behaviour and to disrupt pregnancy in domestic cattle, in which conception rates decrease markedly during the warmest months of the year (Youngquist, 1997).

Periods of interactions with the dominant male lasted up to 12 days, which is about twice as long as the duration of consortship reported by Hitchins and Anderson (1983). This difference may be attributed to the high frequency of observations that were undertaken during the present study. Fighting between the dominant male and another male occurred during such periods of consortship, between 11 and 18 days before a significant increase in faecal progestagen concentrations. This finding indicates that the dominant male tries to prevent other males, including the receptive female's previous calves after they have become sub-adult, from accessing her (sub-adults continue interacting with their mother before reaching sexual maturity; Garnier et al., 2001). However, it is not known whether the dominant male exhibits this behaviour of mate guarding on his home range, as has been reported in white rhinoceros territorial males (Owen-Smith, 1988), or whether he prevents other males from accessing the receptive female within her home range. The observations that two adult females with overlapping home ranges also had the same dominant male and also had overlapping home ranges with that male indicate that a dominant male may become territorial over their common home range when a female becomes receptive (J. N. Garnier, unpublished).

During the gestation period, reproductive activity 
occurred after presumed conception in a wild female, and this activity may contribute towards an explanation of gestation durations of under 14 months noted in black rhinoceroses, which usually have a duration of gestation of approximately 15 months (Hall-Martin and Penzhorn, 1977; Lindemann, 1982; Hitchins and Anderson, 1983; Garnier et al., 1998a; Garnier, 2001). This finding emphasizes the difficulty of diagnosing gestation from behavioural observations only. Such post-conception activity closely resembles that of domestic mares and is probably associated with a temporary surge in oestrogens, identified in a captive black rhinoceros female by Berkeley et al. (1997).

In two females, the marked and rapid decrease in concentrations 2.5-3.5 months after presumed conception associated with the resumption of regular interactions with males is indicative of abortion. This hypothesis is reinforced by the absence of delivery of a calf within 16 months of presumed conception in these two females and by the observation that profiles of faecal progestagen excretion obtained with the same assay as used in pregnant wild black rhinoceros females did not show a decrease in concentrations after the second month of gestation (Garnier et al., 1998a). Abortion has been reported in some captive black rhinoceros and Sumatran females, but mostly in isolated cases (Hodges and Green, 1989; Schwarzenberger et al., 1993, 1996b; Berkeley et al., 1997; Roth et al., 2001). Because the onset of placental steroid production occurs between months 2 and 4 of gestation (Schwarzenberger et al., 1993; Garnier et al., 1998a), this period of pregnancy may represent a vulnerable phase in black rhinoceros females.

The natural incidence of abortion in wild black rhinoceros populations may be higher than previously thought, especially since the two females that aborted during the study belonged to a population that presented good average reproductive performances. This finding emphasizes the importance of using non-invasive reproductive assessment for monitoring individual breeding output in free-ranging endangered wildlife species. In particular, females that have entered post-reproductive life need to be detected. Shenkel and Shenkel-Hulliger (1969) suggested that the reproductive life of wild black rhinoceroses lasts until 30-35 years of age, which is corroborated by observations in the present study that three females estimated to be about 35 years old were still producing calves, although one of these aborted.

The analysis of the timing of reproductive cycles and gestation periods in black rhinoceros females in Zimbabwe indicated that more successful fertilizations took place between November and February, during the summer and rainy season. Despite the limited number of births recorded, the results of the present study support findings from other studies on black and white rhinoceros populations in southern Africa, as well on Indian rhinoceros populations, which identified a calving peak during the wettest months of the year (Joubert and Eloff, 1971; Hall-Martin and Penzhorn, 1977; Laurie 1982; Hitchins and Anderson, 1983; HallMartin, 1986; Owen-Smith, 1988). Such timing of births ensures that temperature and food resources are most suitable for the optimum growth and survival of the young (the rainy season is considered an important factor of influence on reproductive activity in tropical zones; Flowerdew, 1987). Peak conception occurs during the rainy season in a variety of African mammals, including Perissodactyla such as plains zebra and Grevy's zebra (Owen-Smith, 1988; Estes, 1992).

Three nulliparous female rhinoceroses had an interoestrous interval of 3 months in April-June, the onset of which was highly synchronized. The beginning of this anoestrous period coincided with the autumnal equinox in the southern hemisphere (21 March) and its termination corresponded to the winter solstice (21 June). The precise timing of these patterns from one year to another, combined with their synchronization among animals, indicates the occurrence of a seasonal period of reduced reproductive activity during the period of decreasing daylengths in nulliparous females. It could not be determined whether multiparous females also exhibited this seasonal anoestrus, as they were either pregnant or in a phase of postpartum anoestrus. Nevertheless photoperiodicity probably contributes to the regulation of the breeding season in black rhinoceros females. This hypothesis is corroborated by results obtained from captive black rhinoceros females in the northern hemisphere, where all nulliparous females studied presented extended interoestrous intervals of 2-3 months between November and February, whereas multiparous females presented a significantly higher proportion of conceptions during the summer months, except in June (Garnier, 2001). In addition, Radcliffe et al. (2001) reported the formation of large anovulatory follicles during the winter months in a captive black rhinoceros female monitored by ultrasound examination.

Therefore, the seasonal pattern of reproductive activity identified in black rhinoceros females in Zimbabwe may be similar to that occurring in equids, which present a winter anoestrus and a natural breeding season during the spring and summer months (Youngquist, 1997). However, interactions among various environmental factors, such as rainfall, periodicity, temperature and parity, are probably complex. For example, the breeding seasons of pubertal zebu cattle heifers are determined by photoperiodic constraints, whereas by the fifth calving, rainfall has become the factor of overriding influence (Cupps, 1991).

In conclusion, although the number of animals in the present study was limited, the results indicate that black rhinoceros females in the wild exhibit a lactational anoestrus of at least 4 months followed by a period of oestrous cyclicity characterized by a great variability in cycle duration. Photoperiodicity, among other environmental factors such as rainfall and temperature, probably contributes to the regulation of reproductive patterns. This study emphasizes the importance of monitoring naturally occurring patterns of reproductive activity in situ to help in providing a template for breeding programmes of this endangered species. 
The authors are most grateful to C. Stockil, Chairman of the Save Valley Conservancy, for his continuous support and encouragement throughout the study. This study was also made possible by the remarkable skills and dedication of the trackers P. Mukachana, J. Mangava and D. Sighodo. The authors are also grateful to N. Travers, at Imire Game ranch, as well as I. Dupreez, for assistance during the project. The authors extend their thanks to A. Pickard and D. Green for their encouragement and advice during the hormonal analysis. This study was financed by the Zoological Society of London, the Ernest Kleinwort Charitable Trust, Tusk Trust and the North of England Zoological Society. The authors express their sincere thanks to A. Dixon, M. Kleinwort and C. Mayhew for their repeated support and continuous understanding of the numerous constraints associated with rhinoceros research and conservation.

\section{References}

Adcock K (1994) The relevance of territorial behaviour in black rhino to their population management. In Proceeding of a Symposium 'Rhinos as Game Ranch Animals', Onderstepoort pp 82-86

Berkeley EV, Kirkpatrick JF, Schaffer NE, Bryant WM and Threlfall WR (1997) Serum and faecal steroid analysis of ovulation, pregnancy and parturition in the black rhinoceros (Diceros bicornis) Zoo Biology 16 121-132

Brett RA (1998) Mortality factors and breeding performance of translocated black rhinos in Kenya 1984-1995 Pachyderm 26 69-82

Brett RA, Hodges JK and Wanjohi E (1989) Assessment of reproductive status of the black rhinoceros (Diceros bicornis) in the wild Symposium of the Zoological Society of London 61 147-161

Bride L, Emslie R and Brooks M (1996) Proceedings of the 3rd Meeting of the IUCN SSC African Rhino Specialist Group, Itala Game Reserve, South Africa. IUCN/SSC, South Africa

Brinkley HJ (1991) Endocrine signaling and female reproduction Biology of Reproduction 24 22-43

Cupps PT (1991) Reproduction in Domestic Animals 4th Edn, Academic Press, London

Emslie R and Brooks M (1999) African Rhinos. Status and Conservation Action Plan IUCN/SSC African Rhino Specialist Group, Gland, Switzerland

Estes RD (1992) The Behaviour Guide to African Mammals. Including Hoofed Mammals, Carnivores, Primates University of California Press, Los Angeles

Flowerdew JR (1987) Mammals. Their Reproductive Biology and Population Ecology Edward Arnold, London

Foose TJ and Van Strien NJ (1997) Asian Rhinos: Status Survey and Conservation Action Plan IUCN, Gland, Switzerland

Garnier JN (2001) Non-invasive Reproductive Monitoring of Black Rhinoceros Females in the Wild: Patterns of Fertility and the Influence of Environmental Factors DVet Med Thesis, Royal Veterinary College, University of London

Garnier JN, Green DI, Pickard AR, Shaw AJ and Holt WV (1998a) Noninvasive diagnosis of pregnancy in wild black rhinoceros (Diceros bicornis minor) by faecal steroid analysis Reproduction, Fertility and Development 10 451-458

Garnier JN, Holt WV, Pickard AR, Green DI and Shaw AJ (1998b) Steroid stability in the faeces of wild black rhinoceros (Diceros bicornis minor). In Proceedings of the Euro-American Mammal Congress, Santiago de Compostela, Spain July 1998. Abstract 94

Garnier JN, Bruford MW and Goossens B (2001) Mating system and reproductive skew in the black rhinoceros Molecular Ecology $\mathbf{1 0}$ 2031-2041

Goddard J (1966) Mating and courtship of the black rhinoceros East African Wildlife Journal 4 69-75

Goddard J (1967) Home range, behaviour and recruitment rates of two black rhinoceros populations East African Wildlife Journal 5 133-150

Godfrey RW, Srivastava L, Russell PT and Dresser BL (1991) Progress in reproductive physiology research in rhinoceros. In Rhinoceros Biology and Conservation. Proceedings of an International Rhino Conference, San Diego Zoological Society of San Diego, pp 149-152

Göltenboth R (1999) International Studbook for African Rhinoceroses 8th Edn, Zoologischer Garten Berlin AG, Berlin, Germany

Hall-Martin AJ (1986) Recruitment in a small black rhinoceros population Pachyderm 6 7-8

Hall-Martin AJ and Penzhorn BL (1977) Behaviour and recruitment of translocated black rhinoceros Koedoe 20 147-162

Heistermann M, Agil M, Büthe A and Hodges JK (1998) Metabolism and excretion of oestradiol-17 $\beta$ and progesterone in the Sumatran rhinoceros (Dicerorhinus sumatrensis) Animal Reproduction Science 53 $157-172$

Hindle JE (1991) Reproductive Assessment in Female African Rhinoceroses by Urinary Steroid Analysis PhD Thesis, Institute of Zoology, University of London

Hindle JE and Hodges JK (1990) The metabolism of oestradiol-17 $\beta$ and progesterone in the white rhinoceros (Ceratotherium simum simum) Journal of Reproduction and Fertility 90 571-580

Hindle JE, Möstl E and Hodges JK (1992) Measurement of urinary oestrogens and 20 - $\alpha$-dihydroprogesterone during ovarian cycles of black (Diceros bicornis) and white (Ceratotherium simum) rhinoceroses Journal of Reproduction and Fertility 94 237-249

Hitchins PM and Anderson JL (1983) Reproduction, population characteristics and management of the black rhinoceros Diceros bicornis minor in the Hluhluwe/Corridor/Umfolozi game reserve complex South African Journal of Wildlife Research 13 78-85

Hodges JK and Green D (1989) A simplified enzymeimmunoassay for urinary pregnanediol-3-glucuronide: application to reproductive assessment in exotic species Journal of Zoology, London 219 89-99

Joubert E and Eloff FC (1971) Notes on the ecology and behaviour of the black rhinoceros (Diceros bicornis) in South West Africa Madoqua 3 5-53

Kock RA and Garnier JN (1993) Veterinary management of three species of rhinoceroses in zoological collections. In Rhinoceros Biology and Conservation. Proceedings of an International Rhino Conference, San Diego Zoological Society of San Diego pp 325-338

Laurie WA (1982) Behavioural ecology of the greater one-horned rhinoceros Journal of Zoology, London 196 307-342

Lindemann H (1982) African Rhinoceroses in Captivity. The White Rhinoceros Ceratotherium simum (Burchell, 1817). The Black Rhinoceros Diceros bicornis (Linnaeus, 1758) MSc Thesis, University of Copenhagen

Monfort SL Non-invasive endocrine measures of reproduction and stress in wild populations. In Reproductive Sciences and Integrated Conservation Eds WV Holt, AR Pickard, JC Rodger and DE Wildt. Cambridge University Press, Cambridge (in press)

Owen-Smith N (1988) Megaherbivores. The Influence of Very Large Body Size on Ecology Cambridge University Press, Cambridge

Patton ML, Swaisgood RR, Czekala NM, White AM, Fetter GA, Montagne JP, Rieches RG and Lance VA (1999) Reproductive cycle length and pregnancy in the southern white rhinoceros (Ceratotherium simum simum) as determined by fecal pregnane analysis and observations of mating behaviour Zoo Biology 18 111-127

Radcliffe RW, Czekala NM and Osofsky SA (1997) Combined serial ultrasonography and faecal progestin analysis for reproductive evaluation of the female white rhinoceros (Ceratotherium simum simum): preliminary results Zoo Biology 16 445-456

Radcliffe RW, Eyres Al, Patton ML, Czekala NM and Emslie RH (2001) Ultrasonographic characterization of ovarian events and fetal gestational parameters in two southern black rhinoceros (Diceros bicornis minor) and correlation to fecal progesterone Theriogenology $\mathbf{5 5}$ 1033-1049

Rietschel W (2000) Case reports and veterinary aspects of breeding the indian rhino (Rhinoceros unicornis) at Stuttgart Zoo. In Proceedings of the Third Meeting of the European Association of Zoo and Wildlife Veterinarians, Paris pp 195-200

Ritchie AJ (1963) The black rhinoceros (Diceros bicornis) East African Wildlife Journal 1 54-62

Rookmaker LC (1998) The Rhinoceros in Captivity SPB Academic Publishing, Rotterdam 
Roth TL, O'Brien JK, McRae MA, Bellem AC, Romo SJ, Kroll JL and Brown JL (2001) Ultrasound and endocrine evaluation of the ovarian cycle and early pregnancy in the Sumatran rhinoceros, Dicerorhinus sumatrensis. Reproduction 121 139-149

Schwarzenberger F, Francke R and Göltenboth R (1993) Concentrations of faecal immunoreactive progestagen metabolites during the oestrous cycle and pregnancy in the black rhinoceros Diceros bicornis minor. Journal of Reproduction and Fertility 98 285-291

Schwarzenberger F, Möstl E, Palme R and Bamberg E (1996a) Faecal steroid analysis for non-invasive monitoring of reproductive status in farm, wild and zoo animals Animal Reproduction Science 42 515-526

Schwarzenberger F, Tomasova K, Holeckova D, Matern B and Möstl E (1996b) Measurement of faecal steroids in the black rhinoceros (Diceros bicornis) using group-specific enzyme immunoassays for 20-oxopregnanes Zoo Biology 15 159-171

Schwarzenberger F, Walzer C, Tomasova K, Vahala J, Meister J, Goodrowe KL, Zima J, Strauß G and Lynch M (1998) Faecal progesterone metabolite analysis for non-invasive monitoring of reproductive function in the white rhinoceros (Ceratotherium simum) Animal Reproduction Science 53 173-90

Schwarzenberger F, Walzer C, Tomasova K, Zima J, Göritz F, Hermes R and Hildebrandt TB (1999) Can the problems associated with the low reproductive rate in captive white rhinoceros (Ceratotherium simum) be solved within the next 5 years? Erkrankungen der Zootiere 39 283-289
Schwarzenberger F, Rietschel W, Vahala J, Holeckova D, Thomas P, Malzahn J, Baumgartner K and Schaftenaar W (2000) Fecal progesterone, estrogen and androgen metabolites for non-invasive monitoring of reproductive function in the female Indian rhinoceros, Rhinoceros unicornis. General and Comparative Endocrinology 119 300-307

Schwarzenberger F, Walzer C, Jago M, Reinhardt P, Mraz B and Modler F Faecal steroid analysis in free-ranging female white rhinoceros (Ceratotherium simum simum). In Reproductive Sciences and Integrated Conservation Eds WV Holt, AR Pickard, JC Rodger and DE Wildt. Cambridge University Press, Cambridge (in press)

Shenkel R and Shenkel-Hulliger L (1969) Ecology and Behaviour of the Black Rhinoceros (Diceros bicornis): A Field Study Mammalia depicta, Paul Parey, Hambourg and Berlin

Youngquist RS (1997) Current Therapy in Large Animal Theriogenology WB Saunders, Philadelphia

Received 22 August 2001.

First decision 17 October 2001.

Revised manuscript received 11 February 2002.

Accepted 20 February 2002. 